\title{
GERAÇÃO UM DE MAPA HIPSOMÉTRICO DA BACIA HIDROGRÁFICA DE TAQUARITINGA/SP
}

\section{GENERATION ONE OF A HIPSOMETRIC MAP IN THE TAQUARITINGA/SP WATERSHED}

\author{
Gilberto Aparecido Rodrigues - gilberto.rodrigues@fatectq.edu.br \\ Nivaldo Carleto - nivaldo.carleto@fatectq.edu.br \\ Faculdade de Tecnologia de Taquaritinga (Fatec) - Taquaritinga - São Paulo - Brasil \\ Gilmar Oliveira Santos - gilmar@unirv.edu.br \\ Universidade de Rio Verde (UniRV) - Rio Verde - Goiás - Brasil
}

DOI: 10.31510/infa.v17i1.824

\section{RESUMO}

A carta hipsométrica é documento robusto caracterizado por informar a altimetria de uma dada bacia hidrográfica, oferecendo ao usuário uma visão ampla do relevo do terreno. $\mathrm{O}$ objetivo deste estudo foi elaborar mapas com informações sobre o modelo digital de elevação (MDE) e relevo, como base inicial para planejamento da bacia hidrográfica de Taquaritinga (BHT). A metodologia proposta para este estudo é o uso de versões de softwares livres Qgis 3.6 e Google Earth Pro, através da manipulação de imagens de satélite disponíveis gratuitamente em instituições públicas. Os resultados mostram que a área de maior altitude na BHT está localizada na região nordeste da bacia, representando $20 \%$ da área total da bacia. A área mais alta da bacia mostra aparente vulnerabilidade ambiental em termos da densidade visual das áreas de preservação permanente.

Palavras-chave: geotecnologias. hipsometria. unidade hidrológica.

\begin{abstract}
The hypsometric chart is a robust document characterized by informing the altimetry of a given hydrographic basin, offering the user a wide view of the terrain's relief. The purpose of this study was to create maps with information on digital elevation model (DEM) and relief, as an initial basis for planning the Taquaritinga watershed (BHT). The methodology proposed for this study is the use of free software versions Qgis 3.6 and Google Earth Pro, through the manipulation of satellite images available for free at public institutions. The results show that the highest altitude area in BHT is located in the northeast region of the basin, making up $20 \%$ of the total area of the basin. The highest area of the basin shows apparent environmental vulnerability in terms of the visual density of permanent preservation areas.
\end{abstract}

Keywords: geotechnologies. hypsometry. hydrological unit. 


\section{INTRODUÇÃO}

A hipsometria e a declividade do solo são atributos geomorfológicos que permitem a análise e avaliação mais aprofundada da execução do modelo digital de elevação (MDE) de uma dada bacia hidrográfica. A carta hipsométrica é um documento robusto e essencial, caracterizado por informar a altimetria de uma dada área, que propicia ao usuário uma visão ampla do relevo e do rebaixamento do terreno. As análises das bases cartográficas, a elaboração dos mapas hipsométricos e de declividade, permitem a visualização das altitudes e cotas mínimas e máximas da área em estudo. Assim, com o mapa hipsométrico obtém-se uma visão do relevo, caracterizando as suas áreas de planícies aluviais e as demais formas do relevo (SOARES e PIROLI, 2019).

Informações básicas sobre uma bacia hidrográfica no município são interessantes para os gestores públicos em diversos aspectos, sendo ele na condução de um bom planejamento das zonas rurais, principalmente em estudos de levantamento hidrogeológico, por exemplo, é essencial para a delimitação das áreas de recarga e descarga, fluxo da água subterrânea, locais favoráveis e vulneráveis, que associados aos levantamentos de hidrologia, solos e uso do solo, permitem delimitar o zoneamento das áreas de recarga e também os eventuais níveis de restrição do uso de determinadas áreas no meio rural, assim como é possível criar um gerenciamento da água subterrânea da bacia.

Pela Lei do Saneamento ( $\left.\mathrm{n}^{\mathrm{o}} 11.445 / 2007\right)$, que define as diretrizes do saneamento básico, a gestão das águas pluviais é uma atribuição dos municípios. Essa gestão, no entanto, vem sendo feita de forma inadequada devido principalmente à fragmentação das responsabilidades e à falta de planejamento e à gestão por trechos e não por bacias (GUSMÃO e ÁVILA, 2011).

As boas práticas no manejo das águas pluviais têm por base princípios modernos e sustentáveis que levam em consideração a preservação dos mecanismos naturais de escoamento na implementação urbana, a visão de gestão da bacia hidrográfica e o tratamento do esgoto sanitário e da qualidade das águas pluviais (GUSMÃO e ÁVILA, 2011).

Para ampliar os conhecimentos técnicos básicos, desenvolver a base legal e institucional para a correta gestão das águas subterrâneas, o Ministério do Meio Ambiente (MMA) lançou o Programa Nacional de Águas Subterrâneas (PNAS). Este programa, que faz parte do Plano Nacional de Recursos Hídricos (PNRH) estabelece e orienta as políticas para 


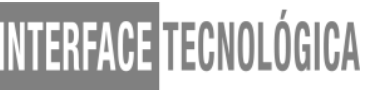

as águas subterrâneas. A água subterrânea é um recurso estratégico principalmente para o consumo humano e um dos principais objetivos da política é o de preservar o recurso natural do ponto de vista econômico, social e ambiental. As águas subterrâneas são de domínio dos estados e o plano traça diretrizes de cooperação entre os entes federados.

Mais de cem municípios paulistas utilizam as águas do Sistema Aquífero Guarani (SAG) para o abastecimento público, por meio da captação de água subterrânea de poços localizados tanto na área de afloramento quanto na área confinada, destacando-se as seguintes cidades, entre outras: Ribeirão Preto (100\%); Araraquara (50\%); São Carlos (50\%); e de São José do Rio Preto (40\%). A porção confinada do SAG se encontra mais protegida de possíveis atividades poluidoras, devido às coberturas de rochas basálticas. Por outro lado, a área de afloramento constitui-se na porção mais vulnerável à entrada de possíveis contaminantes. Nesse sentido, visando à proteção do sistema como um todo, faz-se prioritário o planejamento territorial nessa área (ALBUQUERQUE FILHO et al., 2010; SOUZA, 2014)

Soares e Piroli (2019), elaboraram estudos da bacia hidrográfica da macro região de Botucatu, São Paulo, utilizando software Arcgis 10.3, elaborando mapas de declividade e hipsométricos que permitem assim analisar e decidir o melhor uso e aproveitamento do solo, uma vez que para isso é necessária a compreensão das características físicas ambientais para que se tenha uma melhor adequação a programas municipais de uso do solo.

Por meio do uso dos softwares de geoprocessamento e dos produtos cartográficos disponibilizados pelos órgãos governamentais (EMBRAPA, IBGE, INPE) é possível realizar esse mapeamento, assim como já realizados em outros municípios conforme citado por Alves e Rocha (2015). Neste aspecto, o objetivo deste trabalho foi desenvolver mapas com informações sobre relevo e declividade, como base inicial para planejamento hídrico e ambiental da bacia hidrográfica de Taquaritinga.

\section{PROCEDIMENTOS METODOLÓGICOS}

A metodologia utilizada para realização deste estudo consisti em levantamento bibliográfico, análise de fotografias aéreas de imagens de satélite LANDSAT 8 , acesso ao Banco de Dados Geomorfométricos do Brasil, disponível no projeto Topodata (Figura 1) de acesso livre nos dados do Instituto Nacional de Pesquisas Espaciais (INPE), onde estão disponíveis informações sobre o MDE, e os dados estão estruturados em quadrículas 


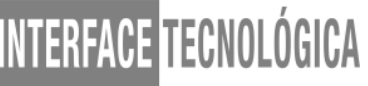

compatíveis com a articulação 1:250.000 em folhas de $1^{\circ}$ de latitude por $1,5^{\circ}$ de longitude. Além disso, é fundamental a inserção destes dados no software livre Qgis 3.6 para a sua manipulação e complementação por interpretação de imagens do Google Earth Pro.

\subsection{USO E APLICAÇÃO DA METODOLOGIA}

Para execução inicial do projeto tem-se de acessar a base de dados do IBGE, onde os arquivos constituem-se de arquivos vetoriais, em formatos DGN, não vinculado a banco de dados, e arquivos de extensões shapefiles (SHP), vinculado a banco de dados, com a divisão das mesorregiões, das microrregiões, dos municípios e dos setores censitários do Brasil, e, para o ano de 2015, estão disponíveis malhas municipais, no sistema de coordenadas geográficas e na projeção Policônica, nas escalas 1:500.000, 1:1.000.000, 1:2.500.000.

Figura 1 - Projeto Topodata com o Modelo Digital de Elevação (MDE) e suas derivações locais básicas em cobertura nacional

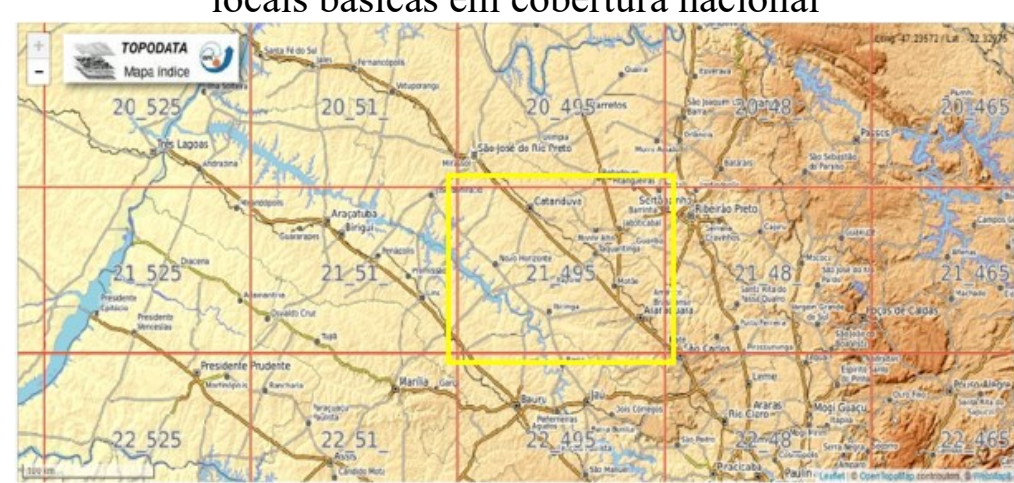

Fonte: http://www.webmapit.com.br/inpe/topodata/

Uma vez identificado o estado, baixa-se os arquivos relacionados aos municípios e inicia-se o projeto, acessando os arquivos SHP, conforme mostra a imagem na Figura 2, onde mostra o município sob estudo. 


\section{WTEERFAET TECNOLLGGCA}

Figura 2 - Arquivos shapefiles dos municípios do estado de São Paulo

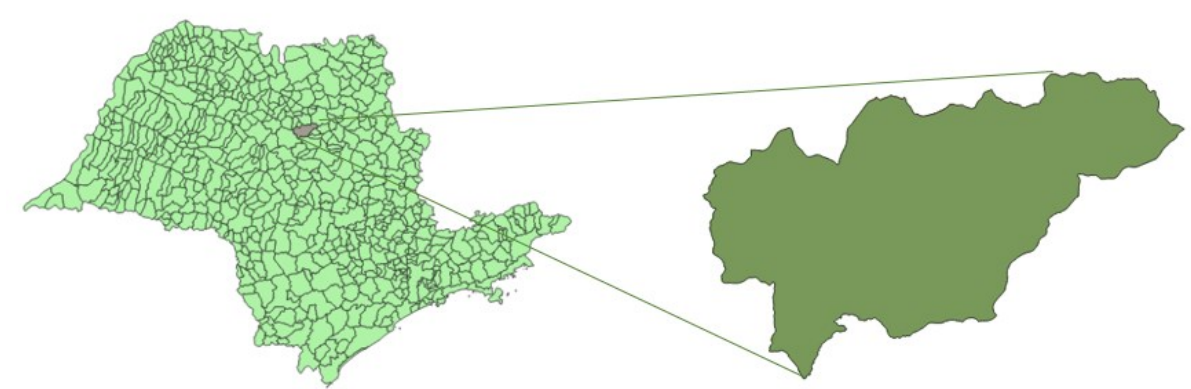

Fonte: https://mapas.ibge.gov.br/bases-e-referenciais/bases-cartograficas/malhas-digitais

Uma vez selecionado o arquivo SHP, vai-se em propriedades, depois acessando a tabela de atributos, e neste momento acessa-se as informações de todos os municípios de do Estado de São Paulo. Por comandos específicos, consegue-se recortar os contornos do município objeto de estudo, como é evidenciado na amplitude do município na Figura 2. Tais arquivos estão projetados num sistema plano, e depois é recomendado mudá-lo para uma projeção em sistema geográfico de coordenadas. Para o arquivo recortado, recomenda-se projetá-lo em um sistema de coordenadas Sirgas 2000, coordenada universal transversor marcator (UTM), no fuso 22 Sul.

Uma vez que se acessa o arquivo do MDE da região de Taquaritinga, o usuário deve alterar o arquivo em Sistema Regional de Coordenada (SRC) geográfico SRC WGS84 para o SRC WGS84 2000/UTM-22S. neste momento tem-se dois arquivos ou duas camadas, uma do município recortado e outra do MDE (Figura 3), ambas no mesmo sistema de referência (WGS84 2000/UTM-22S).

Em seguida, é necessário então fazer o recorte da imagem do arquivo do MDE para o mesmo contorno do município. É através destes dois arquivos que será elaborado então modelo de elevação do solo (MDE) e o mapa hipsométrico do município de Taquaritinga. 


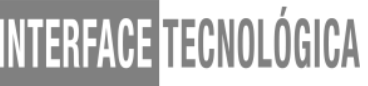

Figura 3 - Mapa do modelo de elevação digital do solo do município de Taquaritinga, São Paulo

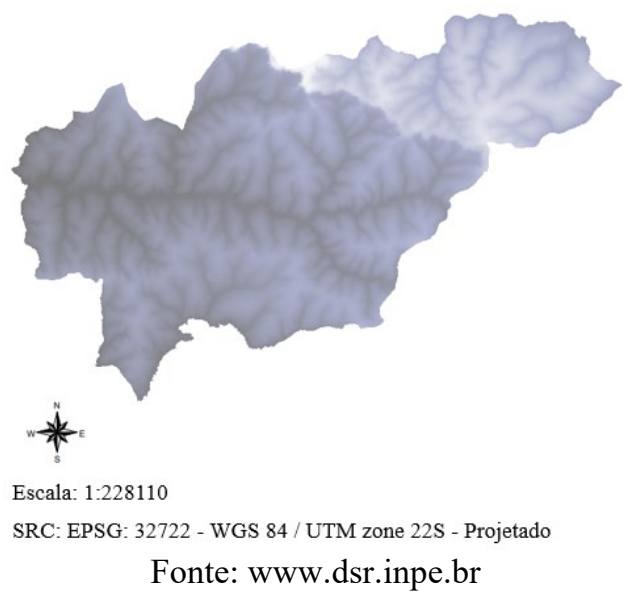

\section{RESULTADOS E DISCUSSÃO}

Após obtidos os dois arquivos recortados, MDE e município, com contornos exatamente idênticos, com resolução espacial de 30m x 30m (1 pixel), tem-se do arquivo MDE a representação das variações das altitudes da bacia hidrográfica de Taquaritinga, num arquivo raster de uma só banda de cor, no caso cinza. Para dar uma melhor visualização e entendimento destas variações de relevo, é possível o uso de comandos onde se usa uma cartela de cores, variando do vermelho, maiores altitudes, até o verde intenso, que representam as baixas altitudes, que é elaborada num arquivo adicionado ao bloco de notas. Assim, obtém-se um mapa com um grid de cores, como mostra a Figura 4.

A Figura 5 apresenta que é possível por comandos específicos realçar o arquivo de MDE raster (Figura 3), de representação continua para um arquivo de representação discreta, através de comando de reclassificação utilizando o algoritmo "r.recode", disponível no complemento do Qgis, denominado "Grass". 
Figura 4 - Mapa hipsométrico através do modelo de elevação do solo do município de Taquaritinga, São Paulo

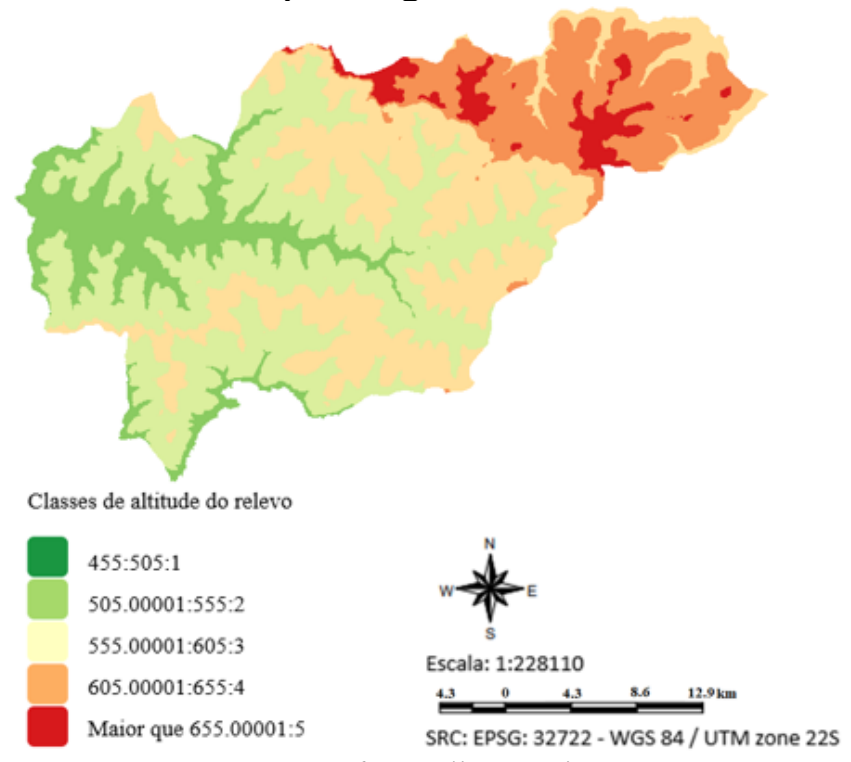

Fonte: Software livre Qgis 3.6

Figura 5 - Representação do MDE do município de Taquaritinga realçando variações do relevo da bacia hidrográfica de Taquaritinga.

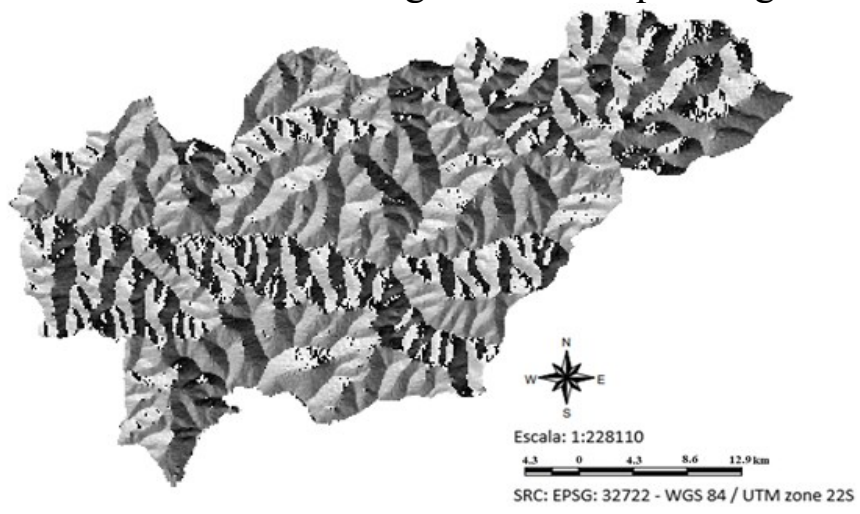

Fonte: Software livre Qgis 3.6

Este algoritmo reclassifica o MDE de acordo com as regras estabelecidas num arquivo reservado no "bloco de notas", onde classifica as altitudes representadas no MDE de acordo com o interesse do usuário. Neste caso específico, estabeleceu-se variações de altitude de 50 em $50 \mathrm{~m}$, ou seja, de $455 \mathrm{~m}$ a $705 \mathrm{~m}$, compreendendo 5 classes de relevo na referida bacia hidrográfica. Utilizando o caminho "propriedades" no arquivo MDE selecionado, na aba estilo é possível definir as bandas de cores (RGB) (Figura 6), e determina-se o raster hipsométrico. 
Figura 6 - Representação do mapa hipsométrico do município de Taquaritinga, São Paulo, realçando variações do relevo da bacia hidrográfica de Taquaritinga

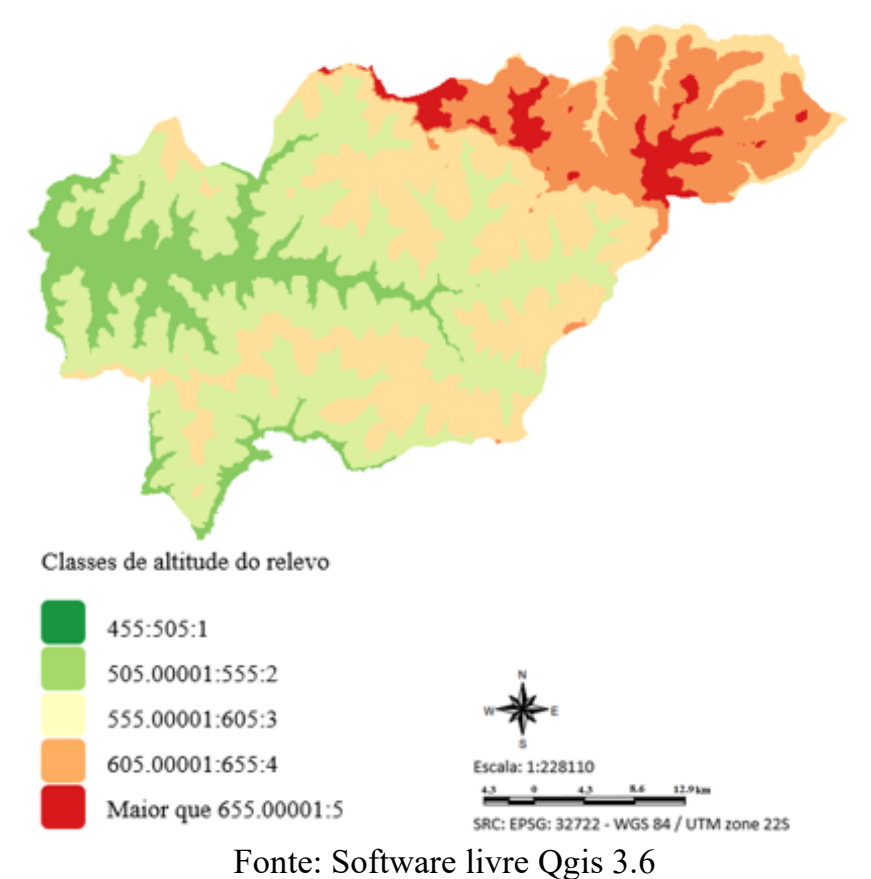

Fonte: Software livre Qgis 3.6

Na Figura 6, fica bem explicito a identificação das áreas da bacia hidrográfica de Taquaritinga (BHT), de relevo de maior altitude. Nas áreas de maior altitude de uma bacia hidrográfica encontra-se grande parte das de nascentes, e é característico destas regiões atuarem como zonas de recarga do aquífero. No caso do município de Taquaritinga, encontrase sobre o Aquífero Bauru. Portanto, é razoável que estas regiões devam ter atenção especial no planejamento rural do município.

Na Figura 7 é demostrado a oportunidade de realçar a visibilidade do mapa hipsométrico com o MDE realçado, ou seja, tanto as cores quentes, tons vermelhos, que indicam maiores altitudes, quanto as cores verdes, tons frios, que indicam menores altitudes, permitem realçar o mapa hipsométrico utilizando o comando "multiplicar" para mostrar o efeito de relevo de montanha.

Através da ferramenta régua, disponível no software Qgis, na Figura 8 é possível identificar aproximadamente a área representada em linha azul, com 13.005,436 ha. Utilizando-se a mesma ferramenta, determina-se a área aproximada do município (59.230,733 ha), onde podemos inferir que esta região de maior altitude representa aproximadamente 21,95\% da área do município de Taquaritinga. 
Figura 7 - Representação do mapa hipsométrico do município de Taquaritinga, São Paulo, combinado com o mapa modelo de elevação do solo com realces de relevo

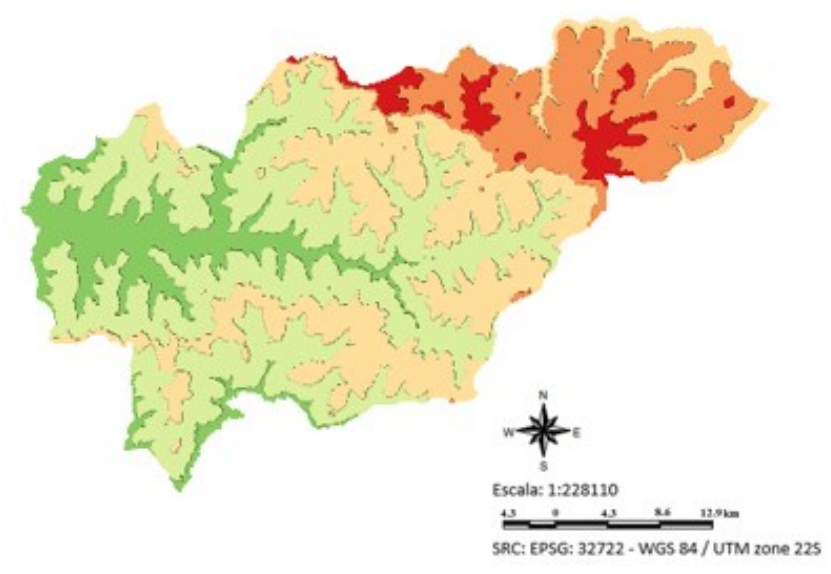

Fonte: Software livre Qgis 3.6

Figura 8 - Determinação da área aproximada da região de maior relevo da bacia hidrográfica do município de Taquaritinga, São Paulo

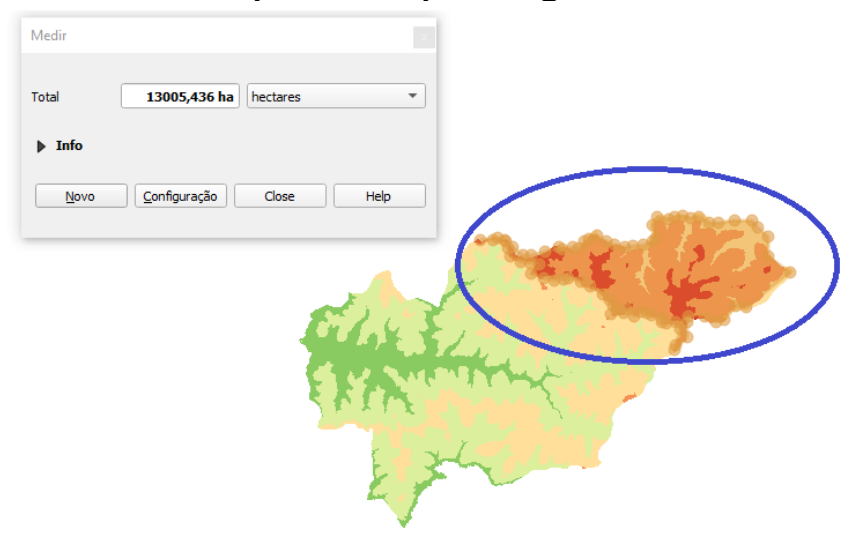

Fonte: Google Earth Pro (2020). Acesso em 08/04/2020.

Nas Figuras 9 e 10, na área delimitada, estima-se área de aproximadamente 13.005,436 ha, e representa uma área exploração exclusivamente agrícola, onde é possível observar que a área é visivelmente rarefeita em áreas de preservação permanente (APP). Na região delimitada, pelas condições de pressão visível pala atividade agrícola, observa-se que, pelas características edafoclimáticas e pela sua maior altitude, trata-se de uma região considerada para possível intervenção pelo poder público, por ser uma zona de recarga do lençol freático para a BHT.

A maioria das nascentes está localizada nas regiões montanhosas, nas chamadas bacias de cabeceira. A água que jorra de uma nascente formará um pequeno ribeirão que irá 
contribuir para o volume de água de outro curso e assim sucessivamente, formando grandes cursos d'água, fundamentais para o abastecimento urbano, agrícola, geração de energia, dentre outros usos. Portanto, o desaparecimento de uma nascente resultará na redução do número de cursos d'água, significando a diminuição da disponibilidade de água para os diversos usos (CASTRO e LOPES, 2001).

Figura 9 - Imagem de satélite disponível no software Google Earth Pro de 06/08/2019

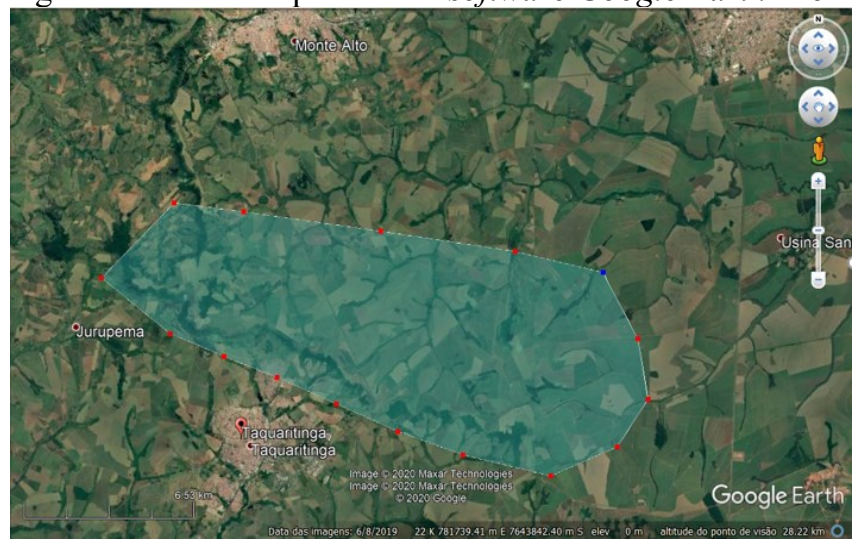

Fonte: Google Earth Pro (2020). Acesso em 08/04/2020.

Figura 10 - Imagem de satélite disponível no software Google Earth Pro de 06/08/2019

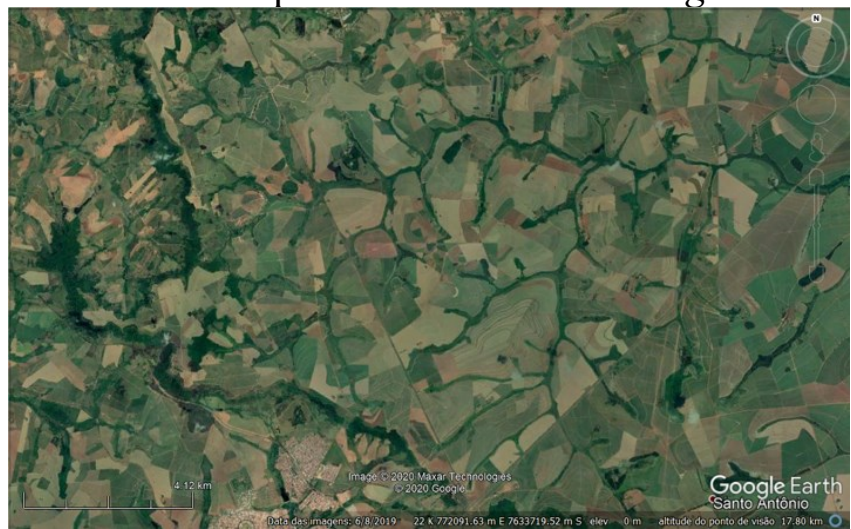

Fonte: Google Earth Pro (2020). Acesso em 08/04/2020.

Neste contexto, os mapas de hipsometria (Figura 6 e 7) gerados neste estudo trazem informações consistentes para o planejamento de todos recursos naturais de toda BHT. Nas Figuras 8 e 9, fica bem visível o aparente raleamento das áreas de APP numa área aproximada de 13 mil hectares, área de maior altitude da bacia, e que com a associação de múltiplas práticas conservacionistas pode propiciar um maior abastecimento do aquífero da bacia, de tal forma que nem abastecimento urbano ou agricultura irrigada, venham a ter prejuízos em períodos de escassez. A bacia hidrográfica pode ser então considerada um ente sistêmico onde 


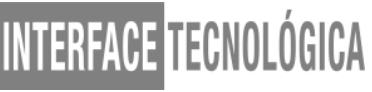

se realizam os balanços de entrada proveniente da chuva e saída de água através do exutório (região de mais baixa altitude na bacia), permitindo que sejam delineadas bacias e sub-bacias, cuja a interconexão se dá pelos sistemas hídricos (TUCCI, 1997; PORTO \& PORTO, 2008).

A região de Taquaritinga encontra-se numa região onde predomina o cultivo da cana de açúcar, e encontra-se numa área designada como mesclada de informações entre áreas consideradas "adequada com limitações ambientais" e "área com restrição ambientais" (IRITANI et al., 2011), em particular ao setor sucroalcooleiro. A quantidade das águas subterrâneas de uma área ou região depende, fundamentalmente, de fatores climáticos e geológicos. Os fatores climáticos determinam a existência ou não de excedente hídrico para alimentar o manancial subterrâneo em consideração. Já o quadro geológico é o determinante fundamental das condições de ocorrência e circulação das águas subterrâneas, acessibilidade da parcela de água meteórica que infiltra, bem como das condições de uso e proteção dos mananciais assim formados, com intuito de garantir a regularidade da oferta de recurso hídrico e a sua qualidade (PERH, 2007, p.71).

Briguenti, Carpi e Dagnino (2007), mapearam os riscos geomorfológicos de uma bacia hidrográfica, através da elaboração de mapas temáticos com as situações de risco ambiental da bacia, abordando: água, ar e poluição atmosférica, solo, agricultura e mineração, vegetação e animais, resíduos e contaminações, e fatores de vulnerabilidade social. Estes autores verificaram que diferentes ambientes com condições naturais específicas, podem ser intensamente comprometidos devido às pressões socioeconômicas provocadas por manejo e/ou uso inadequado dos recursos da bacia hidrográfica, podendo resultar na degradação do ambiente em diferentes magnitudes.

No presente estudo, a elaboração de mapas hipsométricos da BHT é uma importante informação, a qual pode ser associada a uma das vulnerabilidades da BHT, em particular o gerenciamento de resíduos sólidos urbanos, pela presença e uso atual de aterro controlado nesta região de maior altitude (Figura 8), área essa que representa aproximadamente mais de $20 \%$ da área de toda bacia hidrográfica de Taquaritinga. Tal vulnerabilidade tem prováveis implicações na qualidade da água para usos múltiplos na unidade hidrológica como um todo. Outro risco de vulnerabilidade desta região está em uso de fertilizantes nitrogenados, e agroquímicos para o controle pragas e doenças das culturas de cana de açúcar, manga e citros.

De acordo com o novo código florestal, as áreas de preservação permanente (APP) têm a função de preservar os recursos hídricos, a paisagem, a estabilidade geológica, a 


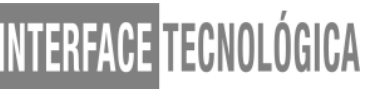

biodiversidade da fauna e da flora, o solo, além de assegurar o bem estar das populações humanas. Assim, toda a vegetação natural, arbórea ou não, ao redor de uma nascente deve ser preservada (MARCUSSI, 2010). O sistema de uma nascente é constituído por vegetação, solo, rochas e relevo das suas áreas adjacentes, denominadas como áreas de recarga. Estas áreas, quando alteradas, para outros usos, fazem com que as nascentes percam a capacidade de "produção de água", comprometendo seu reabastecimento do aquífero (GOMES et al., 2005; RODRIGUES, 2006).

O plano estadual de recursos hídricos (PERH, 2014), que aborda os usos múltiplos e gestão integrada de recursos hídricos, incorpora, essencialmente, ações mínimas de planejamento relacionadas à ampliação, manutenção e aperfeiçoamento do sistema de saneamento básico, à otimização do uso da água, à prevenção e redução dos efeitos dos eventos críticos sobre os recursos hídricos e a população, e ao equilíbrio entre os múltiplos usos da água no Estado de São Paulo (PERH, 2014, p.34). O presente estudo oferece uma contribuição para identificar as áreas prioritárias de recarga hídrica na bacia hidrográfica de Taquaritinga. Oferece também a possibilidade de cadastramento de nascentes na área urbana do município, devendo também cadastrar as nascentes estratégicas localizadas em outras subbacias no município, informações estas que podem dar subsídio à projetos de melhoria hidroambiental da bacia hidrográfica de Taquaritinga.

\section{CONCLUSÃO}

Através dos mapas hipsométricos, conclui-se que há áreas com vulnerabilidade ambiental quanto a densidade visual de áreas de preservação, que se apresentam aparentemente rarefeitas, com exploração de agricultura e dotada de aterro controlado, além de ser propícia ao escoamento superficial e ganho de velocidade da água, o qual pode provocar impactos ambientais, tendo como consequência uma alteração negativa na qualidade da água da área de recarga do aquífero de predomínio da bacia hidrográfica.

Através do uso de ferramentas de geotecnologias de acesso livre é possível determinar com precisão as áreas que, possivelmente, devam sofrer prioridade de intervenção pública para amenizar a maior vulnerabilidade ambiental num custo reduzido. 


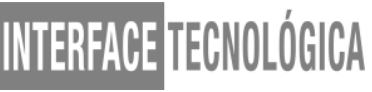

\section{REFERÊNCIAS}

ALVES, W. S.; ROCHA, T. Análise dos aspectos hipsométrico e de exposição do relevo da área urbana de Iporá-GO: Uma contribuição para o estudo do clima das cidades. Anais... In: simpósio INTERNACIONAL DE ÁGUAS, SOLOS E GEOTECNOLOGIAS, SASGEO, 4 a 6 de novembro, Uberaba, Minas Gerais, 2015, 10p.

BRIGUENTI, E. C.; CARPI JÚNIOR, S.; DAGNINO, R. S. Identificação de riscos hidrogeomorfológicos em unidades geossistêmicas da bacia do ribeirão das anhumas, CAMPINAS/SP. In: Anais... XII Simpósio Brasileiro de Geografia Física Aplicada, Natal, RN, 2007. Comunicações Livres - Eixo 9 - A Geografia Física e a gestão das bacias hidrográficas, 9,1629-1648.

GUSMÃO, S. \& ÁVILA, C. Brasil implementa ações para garantir água em quantidade e qualidade. Disponível em: https://www.mma.gov.br/informma/item/6933-brasil-implementaacoes-para-garantir-agua-em-quantidade-e-qualidade. Publicado: Domingo, 20 março 2011 21:00.

PLANO ESTADUAL DE RECURSOS HÍDRICOS: PERH 2012-2015. Relatório de acompanhamento, ano 2012. Governo do Estado de São Paulo, Secretaria de Saneamento e Recursos Hídricos, Coordenadoria de Recursos Hídricos. -- 1. ed. -- São Paulo:

Coordenadoria de Recursos Hídricos, 122p., 2014.

PORTO, M. F. do A. \& PORTO, R. La L. Gestão de bacias hidrográficas. Estudos avançados, v.22, n.63, São Paulo, 2008.

PROJETO AMBIENTAL ESTRATÉGICO AQUÍFEROS: síntese das atividades período 2007 - 2010. Mara Akie Iritani, Luciana Martin Rodrigues Ferreira, Amélia João Fernandes, Sibele Ezaki (orgs). São Paulo: Instituto Geológico, 2011. 144 p. (Cadernos do Projeto Ambiental Estratégico Aquíferos n.3).

SOARES, F. B.; PIROLI, E. L. Análise da hipsometria e da declividade da bacia hidrográfica do rio pardo (São Paulo, Brasil) como subsídio para o planejamento ambiental da área. In:

Anais... XVIII SIMPOSIO BRASILEIRO DE GEOGRAFIA FISICA APLICADA, SBGFA, Fortaleza, Ceará, de 11 a 15 de junho de 2019, 13p.

SOUZA, L. C. de. O disciplinamento da proteção das áreas de afloramento do aquífero guarani no plano diretor do município de Araraquara - SP. Anais... In: XVIII Congresso Brasileiro de Águas Subterrâneas, 14 a 17 de outubro de 2014, Belo Horizonte, MG.

TUCCI, C. E. M. Hidrologia: ciência e aplicação. 2.ed. Porto Alegre: ABRH/Editora da UFRGS, 1997. (Col. ABRH de Recursos Hídricos, v.4). 